\title{
EVALUASI SISTEM PENGENDALIAN INTERN BELANJA SUBSIDI BUNGA KREDIT PROGRAM DI DITJEN PERBENDAHARAAN KEMENTERIAN KEUANGAN
}

\author{
Evaluation on Intern Control System in Expenditure of Credit Program Interest Subsidy in \\ Directorate General of Treasury at The Finance Ministry
}

\section{Samsul Falah', Dedi Budiman Hakim² ${ }^{2}$ A. Faroby Falatehan ${ }^{3}$}

\author{
${ }^{1}$ Staf Direktorat Sistem Manajemen Investasi Ditjen Perbendaharaan Kementerian Keuangan RI. Email: \\ samsul.falah@kemenkeu.go.id \\ 2 Staff Pengajar Departemen Ilmu Ekonomi, Fakultas Ekonomi dan Manajemen. IPB. Email: \\ dbhakim@apps.ipb.ac.id \\ 3 Staff Pengajar Departemen Ekonomi Sumberdaya dan Lingkungan, Fakultas Ekonomi dan Manajemen. IPB \\ Email: f_falatehan@hotmail.com
}

\begin{abstract}
Internal Control System is one of the criteria in giving opinion by the auditing body in Indonesia. Beside that, the government is required to regulated and maintain an Internal Control System within the government as a whole. This study aimed to evaluate the Internal Control System in expenditure of Credit Program Interest Subsidy in Directorate General of Treasury at The Ministry of Finance. In this study, Internal Control System consist of control environment, risk assesssment, control activites, information and communication, and monitoring activities. The Primary data were obtained from questionnaire and interview with financial managers in Credit Program Interest Subsidy in Directorate General of Treasury and official that related in making decisions to make Internal Control System become adequated, while the secondary data were obtained from the reports that associated with Intern Control System and expenditure in Credit Program Interest Subsidy which selected by purposive sampling. The Model was evaluated by Descriptive Analysis and Rating Scale. The Result of this study: (1) From the descriptive analysis has shown that internal control system did not systematic and integrated; (2) Rating scale has shown that the information and communication elements had the lowest value, and indicators human resource guidance from the element of control activities had less value.

Keywords: internal control system, interest subsidy expenditure, rating scale
\end{abstract}

\begin{abstract}
ABSTRAK
Sistem Pengendalian Intern adalah salah satu kriteria dalam pemberian opini yang dilakukan oleh Badan Pemeriksa Keuangan. Disamping itu, pemerintah diharuskan untuk mengatur dan menyelenggarakan sistem pengendalian intern di lingkungan pemerintah secara menyeluruh. Penelitian ini bertujuan untuk mengevaluasi Sistem Pengendalian Intern belanja subsidi bunga kredit program di Direktorat Jenderal Perbendaharaan Kementerian Keuangan. Dalam penelitian ini, Sistem Pengendalian Intern terdiri atas lingkungan pengendalian, penilaian risiko, kegiatan pengendalian, informasi dan komunikasi, dan pemantauan. Data primer diperoleh melalui kuesioner dan wawancara dengan pengelola keuangan belanja subsidi bunga kredit program di Direktorat Jenderal Perbendaharaan, dan pejabat yang terkait dengan pengambilan keputusan agar sistem pengendalian intern menjadi memadai, sedangkan data sekunder diperoleh dari laporan yang terkait sistem pengendalian intern dan belanja subsidi bunga kredit program yang dipilih secara sengaja (purposive sampling). Model dalam penelitian ini dievaluasi dengan analisis deskriptif dan skala rating (rating scale). Hasil dari penelitian ini menunjukkan bahwa Sistem Pengendalian Intern belanja subsidi bunga kredit program tidak sistematis dan terpadu. Skala Rating menunjukkan bahwa unsur informasi dan komunikasi memiliki nilai terendah diantara unsur yang lain dan sub unsur pembinaan sumber daya manusia dari unsur kegiatan pengendalian memiliki nilai terendah.

Kata kunci: sistem pengendalian intern, belanja subsidi bunga, skala rating
\end{abstract}




\section{PENDAHULUAN}

Undang-Undang di bidang keuangan negara telah membawa implikasi perlunya sistem pengelolaan keuangan negara yang lebih akuntabel dan transparan. Dalam pengelolaan keuangan harus dibarengi dengan peningkatan kualitas pengelolaan keuangan pemerintah. Peningkatan kualitas pengelolaan keuangan pemerintah dapat dilaksanakan dengan meningkatkan kinerja, transparansi dan akuntabilitas pengelolaan keuangan negara. Untuk itu Undang-Undang Nomor 1 tahun 2004 mengharuskan pemerintah untuk mengatur dan menyelenggarakan sistem pengendalian intern di lingkungan pemerintah secara menyeluruh. Kemudian dalam Peraturan Pemerintah (PP) Nomor 8 tahun 2006 juga mewajibkan setiap entitas pelaporan dan akuntansi menyelenggarakan sistem pengendalian intern untuk meningkatkan keandalan laporan keuangan dan kinerja.

Sistem pengendalian intern sebagaimana dimaksud dalam UndangUndang Nomor 1 tahun 2004 kemudian ditetapkan melalui Peraturan Pemerintah (PP) Nomor 60 tahun 2008 tentang Sistem Pengendalian Intern Pemerintah (SPIP) yang terdiri dari 5 (lima) unsur penting, yakni: (1) Lingkungan Pengendalian; (2) Penilaian Risiko; (3) Kegiatan Pengendalian; (4) Informasi dan Komunikasi; (5) Pemantauan Pengendalian Intern. Peraturan Pemerintah tentang SPIP ini telah mewajibkan setiap instansi pemerintah untuk membangun SPIP guna mencegah timbulnya kegagalan dan ketidakefisienan dalam pencapaian tujuan organisasi.

Salah satu subsidi yang merupakan komponen pemberdayaan Usaha Mikro Kecil (UMK) dan petani/peternak/ nelayan adalah subsidi bunga kredit program yang dikelola oleh Kementerian Keuangan. Pelaksanaan pengelolaan subsidi bunga kredit program di lingkungan Kementerian Keuangan dilakukan oleh Direktorat Jenderal Perbendaharaan yang dilaksanakan oleh Direktorat Sistem Manajemen Investasi sampai dengan tahun anggaran 2014. Kemudian mulai tahun 2015, pengelolaan subsidi bunga kredit program dilakukan oleh Kantor Pelayanan Perbendaharaan Negara Khusus Investasi.

Rincian pagu anggaran dan realisasi subsidi bunga kredit program meliputi skema Ketahanan Pangan dan Energi (KKP-E), Kredit Pengembangan Energi Nabati dan Revitalisasi Perkebunan (KPEN-RP), Kredit Pemberdayaan Pengusaha Nangroe Aceh Darussalam dan Nias (KPP NAD-Nias), Kredit Usaha Pembibitan Sapi (KUPS), dan Skema Sistem Resi Gudang (S-SRG) yang dikelola oleh Ditjen Perbendaharaan melalui Dit SMI dan KPPN Khusus Investasi dari tahun anggaran 2011 sampai dengan tahun anggaran 2015 seperti terlihat pada Gambar 1

Dari Gambar 1 terlihat bahwa realisasi subsidi bunga kredit program mengalami kenaikan dan penurunan dari tahun anggaran 2011 sampai dengan tahun anggaran 2015, dengan realisasi rata-rata per tahun adalah adalah 335 miliar rupiah.

\begin{tabular}{|c|c|c|c|c|c|c|}
\hline \multirow{5}{*}{$\begin{array}{l}500,000 \\
400,000 \\
300,000 \\
200,000 \\
100,000\end{array}$} & & & & & & \multirow{8}{*}{$\begin{array}{l}\text { Pagu } \\
\text { Realisasi }\end{array}$} \\
\hline & & & & & & \\
\hline & & & & & & \\
\hline & & & & & & \\
\hline & & & & & & \\
\hline- & 2011 & 2012 & 2013 & 2014 & 2015 & \\
\hline Pagu & 473,814 & 364,765 & 356,753 & 407,238 & 424,578 & \\
\hline Realisasi & 276,860 & 301,873 & 296,390 & 401,660 & 400,026 & \\
\hline
\end{tabular}

Gambar 1 Rincian pagu dan realisasi subsidi bunga kredit program yang dikelola Ditjen Perbendaharaan tahun anggaran 20112015 (dalam jutaan rupiah)
Kualitas dari laporan keuangan salah satunya dapat dilihat dari opini yang diberikan oleh Badan Pemeriksa Keuangan (BPK). Opini merupakan 
pernyataan profesional pemeriksa mengenai kewajaran informasi keuangan di dalam laporan keuangan. Kriteria dalam memberikan pernyataan opini tersebut adalah berdasarkan kesesuaian dengan SAP, kecukupan pengungkapan, kepatuhan terhadap peraturan perundangundangan yang berlaku dan efektivitas Sistem Pengendalian Intern (SPI).
Menurut BPK dalam laporan keuangan belanja subsidi bunga kredit program masih terdapat kekurangan mengenai Sistem Pengendalian Intern (SPI) pada belanja subsidi bunga kredit program yang perlu diperbaiki. Berdasarkan Tabel 1 dapat terlihat bahwa sistem pengendalian intern dalam belanja subsidi bunga kredit program perlu dievaluasi.

Tabel 1 Temuan BPK atas LKBUN (999.07) di Ditjen Perbendaharaan

\begin{tabular}{|c|c|c|}
\hline $\mathbf{T A}$ & TEMUAN & URAIAN \\
\hline 2011 & $\begin{array}{l}\text { Sistem } \\
\text { Pengendalian } \\
\text { Intern }\end{array}$ & $\begin{array}{l}\text { Sistem Pencatatan dan Pelaporan Utang Subsidi Kredit Program belum } \\
\text { memadai }\end{array}$ \\
\hline 2012 & $\begin{array}{l}\text { Sistem } \\
\text { Pengendalian } \\
\text { Intern }\end{array}$ & $\begin{array}{l}\text { Pencatatan dan pelaporan utang subsidi bunga kredit program pada Laporan } \\
\text { Keuangan Belanja Subsidi Tahun } 2012 \text { belum memadai. }\end{array}$ \\
\hline 2013 & $\begin{array}{l}\text { Sistem } \\
\text { Pengendalian } \\
\text { Intern }\end{array}$ & $\begin{array}{l}\text { Pengendalian atas Pengelolaan Belanja Subsidi Non Energi Kurang } \\
\text { Memadai sehingga diragukan ketepatan sasarannya (terkait Pengelolaan } \\
\text { Belanja Subsidi Bunga Kredit Program Sebesar Rp 296,14 miliar). }\end{array}$ \\
\hline 2014 & $\begin{array}{l}\text { Sistem } \\
\text { Pengendalian } \\
\text { Intern }\end{array}$ & $\begin{array}{l}\text { Penyaluran Barang/Jasa Bersubsidi oleh Badan Usaha Operator Melampaui } \\
\text { Pagu Anggaran, terkait subsidi bunga kredit program pelampauan realisasi } \\
\text { penyaluran oleh bank pelaksana kepada debitur sebesar Rp910,29 miliar } \\
\text { (terhadap KPA Subsidi Bunga Kredit Program agar melakukan kajian dan } \\
\text { evaluasi atas pengalokasian anggaran disesuaikan dengan Rencana Tahunan } \\
\text { Penyaluran dan kebutuhan kurang bayar tahun sebelumnya) serta } \\
\text { memanfaatkan mekanisme dana cadangan (escrow account) sebagaimana } \\
\text { subsidi lainnya. }\end{array}$ \\
\hline 2015 & $\begin{array}{l}\text { Sistem } \\
\text { Pengendalian } \\
\text { Intern }\end{array}$ & $\begin{array}{l}\text { Kebijakan akuntansi terkait penyajian beban dan utang subsidi belum diatur } \\
\text { secara lengkap. }\end{array}$ \\
\hline
\end{tabular}

Sumber: LHP BPK RI dan Dit SMI tahun 2011 s.d 2015 (diolah)

Sistem Pengendalian Intern Pemerintah (SPIP) merupakan suatu proses yang berjalan terus untuk semakin menyempurnakan pencapaian tujuan organisasi. Kegiatan harus fleksibel dan dapat berubah sesuai dengan kebutuhan, pelaporan keuangan harus semakin andal yang ditunjang dengan Sumber Daya Manusia (SDM) yang semakin profesional dan peralatan yang semakin memadai dan aset semakin aman baik secara administrasi maupun fisik. Selain itu SPIP juga harus ditunjang dengan prosedur pengamanan yang memadai, ditaatinya peraturan yang berlaku dan semakin tingginya integritas aparatur pemerintah (Suwanda D, Dailibas. 2016).

Proses internalisasi Sistem Pengendalian Intern Pemerintah (SPIP) perlu di dukung dengan penerapan hard control berupa Standard Operating Procedure (SOP) dan Satuan Tugas (SATGAS) implementasi SPIP (Hindriani N, Hanafi I Domai T. 2012). Kemudian Erniati (2015) dalam penelitiannya menyimpulkan bahwa sistem pengendalian intern berpengaruh signifikan terhadap kualitas laporan keuangan Satuan Kerja Perangkat Daerah (SKPD) Kabupaten Bulukumba. Kelima unsur dari sistem pengendalian intern 
memberikan kontribusi positif dalam meningkatkan kualitas laporan keuangan SKPD.

Dalil (2013), dalam penelitiannya menyimpulkan bahwa pelaksanaan sistem pengendalian intern pada pelaksanaan pencairan anggaran atas beban APBN di KPPN Jakarta I telah cukup baik. Berdasarkan hal tersebut di atas, tujuan yang ingin dicapai dalam penelitian ini adalah:

1. Mendeskripsikan penerapan sistem pengendalian intern dalam belanja subsidi bunga kredit program berdasarkan Peraturan Pemerintah Nomor 60 Tahun 2008.

2. Mengevaluasi sistem pengendalian intern dalam belanja subsidi bunga kredit program pada pengelola keuangan belanja subsidi bunga kredit program.

\section{METODE PENELITIAN}

Sampel responden yang digunakan pada penelitian ini adalah pengelola keuangan subsidi bunga kredit program di Direktorat Sistem Manajemen Investasi dan pegawai/pejabat KPPN Khusus Investasi terkait belanja subsidi bunga kredit program tahun 2011 sampai dengan 2015 sebanyak 19 responden. Teknik sampling yang digunakan dalam penelitian ini adalah purposive sampling.

Data yang digunakan untuk dianalisis meliputi data primer dan data sekunder yang diperoleh dari pihak-pihak terkait. Teknik pengumpulan data yang dilakukan dalam penelitian ini dilakukan melalui Interview (wawancara), yang dilakukan di tempat kerja informan, dengan tujuan agar diperoleh data dan informasi mengenai sistem pengendalian yang telah dilakukan. Selanjutnya melalui Dokumen, yang dilakukan melalui pengumpulan dokumen yang mendukung pelaksanaan sistem pengendalian intern dalam belanja subsidi bunga kredit program.
Uji instrumen penelitian dilakukan dengan uji validitas data dan uji reliabilitas data dengan bantuan aplikasi IBM SPSS versi 20. Kemudian Metode analisis menggunakan metode deskriptif dengan menginventarisir peraturan dan SOP terkait subsidi bunga kredit program sehingga dapat mendeskripsikan sistem pengendalian intern yang telah dilakukan serta wawancara terhadap pengelola keuangan subsidi bunga kredit program. Untuk mengevaluasi SPI belanja subsidi bunga kredit program, dilakukan dengan menggunakan skala pengukuran rating scale yang menggunakan data primer yang dihasilkan melalui kuesioner yang disebarkan kepada pejabat dan pegawai yang menjadi pengelola keuangan subsidi bunga kredit program dari tahun 2011 sampai dengan tahun 2015 sebagai responden. Isi dari kuesioner tersebut adalah pernyataan yang mewakili unsur dari sistem pengendalian intern belanja subsidi bunga kredit program. Alat analisis yang digunakan untuk membantu perhitungan rating scale adalah Microsoft Excel 2010.

\begin{tabular}{ccc} 
Tabel 2 & $\begin{array}{c}\text { Kriteria penilaian } \\
\text { pengendalian } \\
\text { pemerintah }\end{array}$ & $\begin{array}{c}\text { sistem } \\
\text { intern }\end{array}$ \\
\hline No & $\begin{array}{c}\text { Interval } \\
\text { Penilaian }\end{array}$ & Kriteria \\
\hline 1 & Skor 4 & Sangat Baik \\
2 & Skor $3,00-$ & Baik \\
& 3,99 & \\
3 & Skor $2,00-$ & Kurang \\
& 2,99 & Sangat \\
4 & Skor $1,00-$ & Kurang \\
& 1,99 & S
\end{tabular}

Sumber: Sugiyono (2009) diolah

\section{HASIL DAN PEMBAHASAN}

\section{Penerapan SPI dalam Belanja Subsidi Bunga Kredit Program}

Kementerian

Keuangan menggunakan konsep tiga lini pertahanan dalam memandang implementasi pengendalian intern sebagai lini 
pertahanan tiga lapis termasuk Ditjen

Perbendaharaan, yaitu:

1. Lini pertahanan pertama adalah manajemen dan seluruh pegawai yang melaksanakan proses bisnis. Lini pertahanan ini merupakan pertahanan terpenting dalam mencegah kesalahan, mendeteksi kecurangan, serta mengidentifikasi kelemahan dan kerentanan pengendalian. Dengan demikian, seluruh pimpinan dan pegawai harus memahami dan melaksanakan dengan sungguhsungguh tugas dan tanggung jawab pengendalian kegiatan masingmasing.

2. Lini pertahanan kedua merupakan fungsi pemantauan. Dalam konteks pengendalian intern di Kementerian Keuangan, fungsi ini dijalankan oleh Unit Kepatuhan Internal (UKI) yang bertugas memantau pengendalian intern di setiap tingkatan manajemen. Unit pertahanan ini harus memperingatkan lini pertahanan pertama apabila dijumpai kelemahan pengendalian intern baik dari segi tahapan rancangan sampai dengan tahapan pelaksanaannya.

3. Lini pertahanan ketiga adalah fungsi auditor internal. Dalam konteks pengendalian intern di Kementerian Keuangan, fungsi ini dijalankan oleh Inspektorat Jenderal untuk peningkatan pengendalian intern dan memperbaiki kekurangan.
Penerapan Sistem Pengendalian Intern (SPI) belanja subsidi bunga kredit program tidak terlepas dari SPI yang ada di Kementerian Keuangan. Selain itu, penerapan SPI dalam belanja subsidi bunga kredit program sangat erat kaitannya dengan SOP dan peraturan yang dilakukan mulai dari tahap perencanaan sampai dengan tahap pelaporan melalui review yang dilakukan Inspektorat Jenderal Kementerian Keuangan. Penerapan Sistem Pengendalian Intern (SPI) belanja subsidi bunga kredit program dilakukan melalui penerapan unsur-unsur Sistem Pengendalian Intern (SPI) dan dengan konsep tiga lini pertahanan yang telah ditetapkan Kementerian Keuangan, namun belum sistematis dalam pelaksanaannya karena tidak dilakukan secara rutin baik oleh kepatuhan internal yang ada di Direktorat Sistem Manajemen Investasi maupun Unit Kepatuhan Internal yang ada di KPPN Khusus Investasi. Kemudian sistem pengendalian intern yang ada dilakukan secara terpisah diantara masing-masing unsur sistem pengendalian intern yang seharusnya dapat menjadi satu dalam laporan sistem pengendalian intern belanja subsidi bunga kredit program.

\section{Evaluasi SPI dalam Belanja Subsidi Bunga Kredit Program pada Pengelola Keuangan}

\section{Hasil Uji Validitas item (Tabel 3)}

\section{Tabel 3 Hasil Uji Validitas Item}

\begin{tabular}{|c|c|c|c|c|c|c|}
\hline No & Unsur SPI & $\begin{array}{c}\text { Jumlah } \\
\text { Pernyataan }\end{array}$ & $\begin{array}{c}\text { Jumlah } \\
\text { Responden }\end{array}$ & $r$ hitung & $r$ tabel & Ket \\
\hline 1 & $\begin{array}{l}\text { Lingkungan } \\
\text { Pengendalian }\end{array}$ & 24 & 19 & 0.514 s.d 0.864 & 0.456 & Valid \\
\hline 2 & Penilaian Risiko & 7 & 19 & 0.745 s.d 0.955 & 0.456 & Valid \\
\hline 3 & $\begin{array}{l}\text { Kegiatan } \\
\text { Pengendalian }\end{array}$ & 22 & 19 & 0.504 s.d 0.875 & 0.456 & Valid \\
\hline 4 & $\begin{array}{l}\text { Informasi \& } \\
\text { Komunikasi }\end{array}$ & 5 & 19 & 0.684 s.d 0.883 & 0.456 & Valid \\
\hline 5 & Pemantauan & 6 & 19 & 0.688 s.d 0.859 & 0.456 & Valid \\
\hline
\end{tabular}


Berdasarkan Tabel 3, dapat terlihat bahwa dari masing-masing pernyataan yang mewakili dari masing masing unsur Sistem Pengendalian Intern (SPI) yang diajukan kepada responden adalah valid yang diperoleh dengan pengolahan menggunakan IBM SPSS Statistic 20, yang menghasilkan 64 pernyataan dinyatakan valid yang didasarkan karena $r$ hitung lebih besar dari $r$ tabel. Hal ini menunjukkan adanya dukungan item tersebut dalam suatu hal yang ingin diungkap.

\section{Hasil Uji Reliabilitas}

Tabel 4 Hasil Uji Reliabilitas Item

\begin{tabular}{|c|c|c|c|c|}
\hline No & Unsur SPI & $\begin{array}{c}\text { Jumlah } \\
\text { Pertanyaan }\end{array}$ & r hitung & Keterangan \\
\hline 1 & $\begin{array}{l}\text { Lingkungan } \\
\text { Pengendalian }\end{array}$ & 24 & 0.955 & reliabel \\
\hline 2 & Penilaian Risiko & 7 & 0.936 & reliabel \\
\hline 3 & $\begin{array}{c}\text { Kegiatan } \\
\text { Pengendalian }\end{array}$ & 22 & 0.960 & reliabel \\
\hline 4 & $\begin{array}{l}\text { Informasi \& } \\
\text { Komunikasi }\end{array}$ & 5 & 0.797 & reliabel \\
\hline 5 & Pemantauan & 6 & 0.864 & reliabel \\
\hline
\end{tabular}

Berdasarkan Tabel 4, hasil uji reliabilitas dengan IBM SPSS Statistic 20 dapat terlihat bahwa $r$ hitung dalam ukuran kemantapan alpha 0,79 sampai dengan 0,96 sehingga dapat disimpulkan bahwa pernyataan yang ada di dalam kuesioner reliabel karena nilai $\mathrm{r}$ hitung lebih besar dari 0.60 .

\section{Unsur Lingkungan Pengendalian}

Pengukuran yang dilakukan terhadap persepsi responden, diperoleh hasil bahwa jumlah skor total yang diperoleh dari pengisian kuesioner dari keseluruhan lingkungan pengendalian adalah sebesar 1.514 dengan prosentase Total Capaian Responden (TCR) sebesar $83 \%$ dari skala kriterium atau 3,32 (likert skala 4) sebagaimana disajikan pada Tabel 5.

Tabel 5 Persepsi Responden Terhadap Lingkungan Pengendalian

\begin{tabular}{|c|c|c|c|c|c|c|c|}
\hline $\begin{array}{l}\mathbf{N} \\
\mathbf{0}\end{array}$ & Indikator & $\begin{array}{c}\text { Pertanyaa } \\
\text { n }\end{array}$ & $\begin{array}{c}\text { Nila } \\
\text { i }\end{array}$ & $\begin{array}{l}\text { Rata- } \\
\text { rata }\end{array}$ & $\begin{array}{l}\text { Skor } \\
\text { Ideal }\end{array}$ & $\begin{array}{l}\text { TCR } \\
(\%)\end{array}$ & $\begin{array}{c}\text { Kriteri } \\
\text { a }\end{array}$ \\
\hline \multirow[t]{3}{*}{1} & Penegakan & 1 & 3.37 & & & & \\
\hline & Integritas dan & 2 & 3.42 & & & & \\
\hline & Nilai Etika & 3 & 3.58 & 3.46 & 4 & 86.40 & Baik \\
\hline \multirow[t]{5}{*}{2} & Komitmen & 5 & 3.32 & & & & \\
\hline & Terhadap & 6 & 3.53 & & & & \\
\hline & Kompetensi & 7 & 2.79 & 3.29 & 4 & 82.37 & Baik \\
\hline & & 8 & 3.53 & & & & \\
\hline & & 9 & 3.32 & & & & \\
\hline \multirow[t]{3}{*}{3} & Kepemimpinan & 11 & 3.42 & & & & \\
\hline & yang Kondusif & 12 & 3.32 & 3.44 & 4 & 85.96 & Baik \\
\hline & & 13 & 3.58 & & & & \\
\hline \multirow[t]{3}{*}{4} & Struktur & 14 & 3.53 & & & & \\
\hline & Organisasi & 15 & 3.32 & 3.35 & 4 & 83.77 & Baik \\
\hline & & 16 & 3.21 & & & & \\
\hline
\end{tabular}




\begin{tabular}{|c|c|c|c|c|c|c|c|}
\hline \multirow[t]{6}{*}{5} & \multirow{6}{*}{$\begin{array}{l}\text { Pendelegasian } \\
\text { Wewenang dan } \\
\text { Tanggung Jawab }\end{array}$} & 17 & \multicolumn{5}{|l|}{3.37} \\
\hline & & 18 & \multicolumn{5}{|l|}{3.42} \\
\hline & & 19 & \multicolumn{5}{|l|}{3.32} \\
\hline & & 20 & 2.63 & 3.11 & 4 & 77.85 & Baik \\
\hline & & 21 & 2.95 & & & & \\
\hline & & 22 & 3.00 & & & & \\
\hline \multirow[t]{6}{*}{6} & \multirow{2}{*}{\multicolumn{7}{|c|}{$\begin{array}{l}\text { Perwujudan } \\
\text { Aparat }\end{array}$}} \\
\hline & & & & & & & \\
\hline & Pengawasan & 24 & 3.37 & 3.39 & 4 & 84.87 & Baik \\
\hline & Internal & & & & & & \\
\hline & Pemerintah yang & & & & & & \\
\hline & Efektif & & & & & & \\
\hline \multirow[t]{4}{*}{7} & Hubungan Kerja & 25 & 3.53 & & & \multirow{3}{*}{87.50} & \multirow{3}{*}{ Baik } \\
\hline & $\begin{array}{l}\text { yang Baik dengan } \\
\text { Instansi }\end{array}$ & 26 & 3.47 & 3.50 & 4 & & \\
\hline & Pemerintah terkait & & & & & & \\
\hline & Rata-rata & & 3.32 & & 4 & 83.00 & Baik \\
\hline
\end{tabular}

\section{Unsur Penilaian Risiko}

Dalam unsur ini yang dilihat adalah kemampuan Dit SMI dan KPPN Khusus Investasi dalam melakukan identifikasi risiko dan analisis risiko. Berdasarkan pengukuran yang dilakukan sesuai Tabel 6, diperoleh hasil bahwa jumlah skor total yang diperoleh dari pengisian kuesioner dari keseluruhan unsur penilaian risiko sebesar 426 dengan prosentase sebesar $80,08 \%$ dari skala kriterium 3,20 (likert skala 4).

Tabel 6 Persepsi Responden Terhadap Penilaian Risiko

\begin{tabular}{cccccccc}
\hline No & \multicolumn{1}{c}{ Indikator } & Pertanyaan & Nilai & Rata-rata & Skor Ideal & $\begin{array}{c}\text { TCR } \\
(\mathbf{\%})\end{array}$ & Kriteria \\
\hline 1 & Identifikasi & 1 & 3.21 & & & & \\
& Risiko & $\mathbf{2}$ & $\mathbf{3 . 1 6}$ & & & & \\
& & $\mathbf{3}$ & $\mathbf{3 . 1 6}$ & $\mathbf{3 . 1 8}$ & $\mathbf{4}$ & $\mathbf{7 9 . 3 9}$ & Baik \\
& \multirow{2}{*}{ Analisis Risiko } & 4 & 3.37 & & & & \\
& & 5 & 3.21 & & & & \\
& & 6 & 3.11 & 3.22 & 4 & & Baik \\
& & 7 & 3.21 & & & & Baik \\
\hline
\end{tabular}

Hal ini menunjukkan bahwa unsur penilaian risiko dalam pengelolaan belanja subsidi bunga kredit program telah berjalan dengan baik.

\section{Unsur Kegiatan Pengendalian}

Hasil pengukuran unsur kegiatan pengendalian sebagaimana tampak pada Tabel 7. Dalam unsur ini yang dilihat adalah review kinerja, pembinaan SDM, Pengendalian atas pengelolaan sistem informasi, Pengendalian fisik atas aset, penetapan review kinerja, pemisahan fungsi, otorisasi atas transaksi dan kejadian yang penting, pencatatan yang akurat dan tepat, serta dokumentasi yang baik. Hasil perolehan berdasarkan persepsi responden seperti tampak pada Tabel 7 menunjukkan skor total yang diperoleh dari pengisian kuesioner keseluruhan unsur kegiatan pengendalian sebesar 1423 dengan prosentase sebesar $85.11 \%$ dari skala kriterium 3.40 (likert skala 4). Hal ini menunjukkan bahwa unsur kegiatan pengendalian telah berjalan dengan baik. Namun terdapat salah satu sub unsur yang bernilai kurang 
dengan prosentase Total Capaian Responden (TCR) sebesar $73.68 \%$ dari skala kriterium 2.95 (likert skala 4) dalam pembinaan SDM terkait pengadaan pelatihan guna meningkatkan pengetahuan pegawai dalam pengelolaan belanja subsidi bunga kredit program.

Tabel 7 Persepsi Responden Terhadap Unsur Kegiatan Pengendalian

\begin{tabular}{|c|c|c|c|c|c|c|c|}
\hline $\begin{array}{l}\mathbf{N} \\
\mathbf{0}\end{array}$ & Indikator & $\begin{array}{c}\text { Pertanyaa } \\
\text { n }\end{array}$ & $\begin{array}{c}\text { Nila } \\
\text { i }\end{array}$ & $\begin{array}{c}\text { Rata- } \\
\text { rata }\end{array}$ & $\begin{array}{l}\text { Skor } \\
\text { Ideal }\end{array}$ & $\begin{array}{l}\text { TCR } \\
(\%)\end{array}$ & $\begin{array}{l}\text { Kriteri } \\
\quad \mathbf{a}\end{array}$ \\
\hline 1 & Review Kinerja & 1 & 3.63 & 3.63 & 4 & $\begin{array}{c}90.7 \\
9\end{array}$ & Baik \\
\hline 2 & Pembinaan SDM & $\begin{array}{l}2 \\
3\end{array}$ & $\begin{array}{l}3.11 \\
2.79\end{array}$ & 2.95 & 4 & $\begin{array}{c}73.6 \\
8\end{array}$ & Kurang \\
\hline 3 & $\begin{array}{l}\text { Pengendalian atas } \\
\text { Sistem Informasi }\end{array}$ & $\begin{array}{l}4 \\
5 \\
6\end{array}$ & $\begin{array}{l}3.32 \\
3.42\end{array}$ & & & 83.8 & \\
\hline 4 & $\begin{array}{l}\text { Pengendalian Fisik atas } \\
\text { Aset }\end{array}$ & $\begin{array}{l}7 \\
8 \\
9\end{array}$ & $\begin{array}{l}3.32 \\
3.37 \\
3.37\end{array}$ & 3.36 & 4 & 80.9 & Baik \\
\hline 5 & $\begin{array}{l}\text { Penetapan dan Review } \\
\text { kineria }\end{array}$ & $\begin{array}{l}10 \\
11\end{array}$ & $\begin{array}{l}3.11 \\
3.58\end{array}$ & 3.24 & 4 & $\begin{array}{c}2 \\
89.4\end{array}$ & Baik \\
\hline 6 & Pemisahan Fungsi & $\begin{array}{l}12 \\
13\end{array}$ & $\begin{array}{l}3.58 \\
3.32\end{array}$ & 3.58 & & $\begin{array}{c}7 \\
84.2\end{array}$ & Baik \\
\hline 7 & $\begin{array}{l}\text { Otorisasi atas } \\
\text { Transaksi dan Kejadian } \\
\text { Penting }\end{array}$ & $\begin{array}{l}14 \\
15 \\
16\end{array}$ & $\begin{array}{l}3.42 \\
3.63 \\
3.53\end{array}$ & 3.37 & 4 & 89.8 & Baik \\
\hline & & 17 & $\begin{array}{l}3.58 \\
3.63\end{array}$ & 3.59 & 4 & 0 & Baik \\
\hline 8 & $\begin{array}{l}\text { Pencatatan yang } \\
\text { Akurat dan Tepat }\end{array}$ & $\begin{array}{l}18 \\
19\end{array}$ & 3.47 & & & 87.2 & \\
\hline & & 20 & $\begin{array}{l}3.63 \\
3.37 \\
3.27\end{array}$ & 3.49 & 4 & 8 & Baik \\
\hline 9 & $\begin{array}{l}\text { Dokumentasi yang } \\
\text { Baik }\end{array}$ & $\begin{array}{l}21 \\
22\end{array}$ & $\begin{array}{l}3.37 \\
3.37\end{array}$ & 3.37 & 4 & $\begin{array}{c}84.2 \\
1\end{array}$ & Baik \\
\hline & Rata-rata & & 3.40 & & 4 & $\begin{array}{c}85.1 \\
1\end{array}$ & Baik \\
\hline
\end{tabular}

\section{Unsur Informasi dan Komunikasi}

Unsur keempat dari sistem pengendalian intern adalah informasi dan komunikasi. Dalam unsur ini menekankan bagaimana Dit SMI dan KPPN Khusus Investasi dalam penyediaan sarana komunikasi, pengelolaan dan pengembangan sistem informasi.
Berdasarkan pengukuran yang dilakukan sesuai Tabel 8, diperoleh hasil bahwa jumlah skor total yang diperoleh dari pengisian kuesioner terkait unsur informasi dan komunikasi sebesar 303 dengan prosentase TCR sebesar $79.74 \%$ dari skala kriterium 3.19 (likert skala 4). 
Tabel 8 Persepsi Responden Terhadap Unsur Informasi dan Komunikasi

\begin{tabular}{clcccccc}
\hline No & \multicolumn{1}{c}{ Indikator } & Pertanyaan & Nilai & $\begin{array}{c}\text { Rata- } \\
\text { rata }\end{array}$ & $\begin{array}{c}\text { Skor } \\
\text { Ideal }\end{array}$ & $\begin{array}{c}\text { TCR } \\
(\boldsymbol{\%})\end{array}$ & Kriteria \\
\hline 1 & Tersedianya sarana & 1 & 3.37 & & & & \\
& komunikasi & 2 & 3.11 & & & & \\
\multirow{2}{*}{2} & 3 & 3.16 & 3.21 & 4 & 80.26 & Baik \\
& $\begin{array}{l}\text { Pengelolaan } \\
\text { \&Pengembangan }\end{array}$ & 4 & 3.21 & & & & \\
& Sistem Informasi & $\mathbf{5}$ & $\mathbf{3 . 1 1}$ & $\mathbf{3 . 1 6}$ & $\mathbf{4}$ & $\mathbf{7 8 . 9 5}$ & Baik \\
\hline & \multirow{2}{*}{ Rata-rata } & $\mathbf{6}$ & $\mathbf{3 . 1 9}$ & & $\mathbf{4}$ & $\mathbf{7 9 . 7 4}$ & Baik \\
\hline
\end{tabular}

Hasil perolehan berdasarkan persepsi responden seperti tampak pada Tabel 8, menunjukkan bahwa unsur informasi dan komunikasi telah berjalan dengan baik. Untuk mencapai kondisi yang lebih baik, dapat ditingkatkan melalui sub unsur pengelolaan dan pengembangan sistem informasi yang mempunyai prosentase TCR sebesar 78.95\% dari skala kriterium 3.16 (likert skala 4). Nilai prosentase sub unsur pengelolaan dan pengembangan sistem informasi lebih rendah apabila dibandingkan dengan sub unsur lainnya dalam unsur informasi dan komunikasi.

\section{Unsur Pemantauan}

Unsur pemantauan merupakan unsur kelima dari sistem pengendalian intern. Pemantauan merupakan proses penilaian atas mutu kerja sistem pengendalian intern dan proses yang memberikan keyakinan bahwa temuan audit dan evaluasi lainnya segera ditindaklanjuti.

Berdasarkan pengukuran yang dilakukan diperoleh hasil bahwa jumlah skor total yang diperoleh dari pengisian kuesioner terkait unsur pemantauan sebesar 377dengan prosentase Total Capaian Responden (TCR) sebesar 82.68\% dari skala kriterium 3.31 (likert skala 4), seperti terlihat pada Tabel 9.

Tabel 9 Persepsi Responden Terhadap Unsur Pemantauan

\begin{tabular}{llcccccc}
\hline No & Indikator & Pertanyaan & Nilai & $\begin{array}{c}\text { Rata- } \\
\text { rata }\end{array}$ & $\begin{array}{c}\text { Skor } \\
\text { Ideal }\end{array}$ & $\begin{array}{c}\text { TCR } \\
(\boldsymbol{\%})\end{array}$ & Kriteria \\
\hline 1 & Pemantauan & 1 & 3.26 & & & & \\
& Berkelanjutan & $\mathbf{2}$ & $\mathbf{3 . 1 1}$ & & & & \\
& & 3 & 3.42 & $\mathbf{3 . 2 6}$ & $\mathbf{4}$ & $\mathbf{8 1 . 5 8}$ & Baik \\
& Evaluasi Terpisah & 4 & 3.32 & & & & \\
& & 5 & 3.26 & & & & \\
& & 6 & 3.47 & 3.35 & 4 & 83.77 & Baik \\
\hline & & & $\mathbf{3 . 3 1}$ & & $\mathbf{4}$ & $\mathbf{8 2 . 6 8}$ & Baik \\
\hline
\end{tabular}

Hasil perolehan berdasarkan persepsi responden ini menunjukkan bahwa unsur pemantauan telah berjalan dengan baik. Namun demikian, untuk mencapai kondisi yang lebih baik, dapat ditingkatkan melalui sub unsur 32 pemantauan berkelanjutan yang mempunyai prosentase Total Capaian Responden (TCR) sebesar $81.58 \%$ dari skala kriterium 3.26 (likert skala 4). Nilai prosentase sub unsur pemantauan berkelanjutan lebih rendah apabila dibandingkan dengan sub unsur lainnya dalam unsur pemantauan.

Ikhtisar

Seluruh unsur sistem pengendalian intern yang terdiri dari lingkungan pengendalian, penilaian risiko, kegiatan 
pengendalian, informasi dan komunikasi, dan pemantauan telah berjalan dengan baik. Hal ini dibuktikan bahwa dari 64 pertanyaan yang disampaikan, skor kriterium yang diperoleh secara keseluruhan adalah 4043 dengan persentase Total Capaian Responden (TCR) sebesar $83.12 \%$ dari skala kriterium 3.32 (likert skala 4).

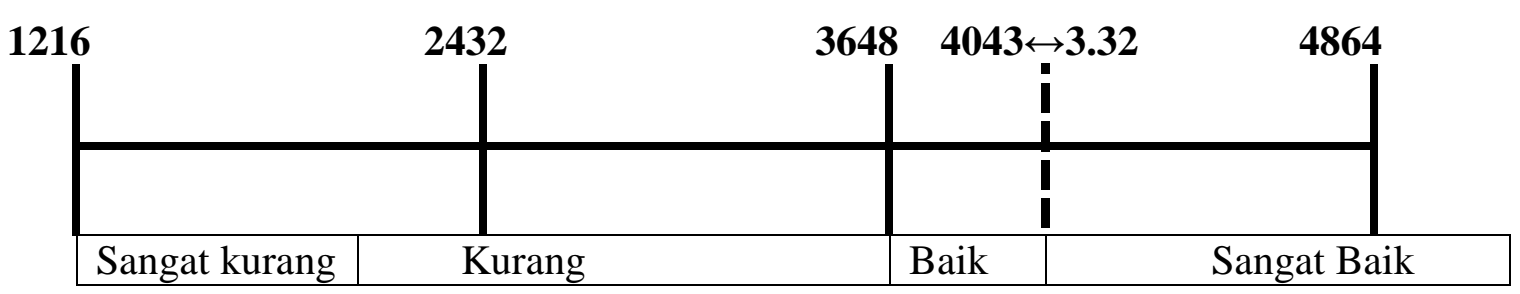

Berdasarkan analisis dari kelima unsur sistem pengendalian intern yang sudah diuraikan sebelumnya sebagaimana Tabel 10, maka dapat diketahui bahwa nilai terendah dari seluruh unsur Sistem Pengendalian Intern adalah unsur
Informasi dan Komunikasi, hal ini dikarenakan sistem informasi yang ada hanya dapat digunakan sebatas pembayaran subsidi bunga dan tidak terkait verifikasi tagihan subsidi bunga serta pengujian ketepatan sasaran.

Tabel 10 Hasil Rating Scale masing-masing unsur SPI pada responden

\begin{tabular}{clcccc}
\hline No & \multicolumn{1}{c}{ Unsur SPI } & Nilai & Skor Ideal & TCR $(\%)$ & Kriteria \\
\hline 1 & Lingkungan Pengendalian & $\mathbf{3 . 3 2}$ & $\mathbf{4}$ & $\mathbf{8 3 . 0 0}$ & Baik \\
2 & Penilaian Risiko & $\mathbf{3 . 2 0}$ & $\mathbf{4}$ & $\mathbf{8 0 . 0 8}$ & Baik \\
3 & Kegiatan Pengendalian & $\mathbf{3 . 4 0}$ & $\mathbf{4}$ & $\mathbf{8 5 . 1 1}$ & Baik \\
4 & Informasi \& Komunikasi & $\mathbf{3 . 1 9}$ & $\mathbf{4}$ & $\mathbf{7 9 . 7 4}$ & Baik \\
5 & Pemantauan & $\mathbf{3 . 3 1}$ & $\mathbf{4}$ & $\mathbf{8 2 . 6 8}$ & Baik \\
\hline
\end{tabular}

Indikator Pembinaan SDM dalam unsur kegiatan pengendalian menghasilkan nilai yang masih kurang seperti tampak pada Tabel 7. Hal ini disebabkan karena tidak adanya pelatihan terkait pengelolaan subsidi bunga kredit program untuk pengelola keuangan belanja subsidi bunga kredit program ketika masih dikelola oleh Direktorat Sistem Manajemen Investasi maupun sesudah dikelola oleh KPPN Khusus Investasi.

\section{Implikasi Kebijakan}

Berdasarkan hasil dan pembahasan penelitian ini berupaya mengevaluasi sistem pengendalian intern belanja subsidi bunga kredit program sehingga dapat menunjukkan hal-hal yang harus diperhatikan dan diperbaiki oleh manajemen yang terlibat dalam belanja subsidi bunga kredit program. Hal-Hal yang perlu diperhatikan dan harus diperbaiki menurut penelitian ini adalah:

1. Pembuatan peraturan terkait pelaksanaan pengendalian intern belanja subsidi bunga kredit program agar sistematis dan terpadu yang melibatkan manajemen belanja subsidi bunga kredit program, Unit Kepatuhan Internal (UKI) di Ditjen Perbendaharaan dan Inspektorat Jenderal Kementerian Keuangan sehingga menjadi satu rangkaian yang utuh.

2. Unsur informasi dan Komunikasi harus memperoleh perhatian karena memiliki nilai yang lebih rendah dibandingkan dengan unsur yang lain 
khususnya dalam pengelolaan dan pengembangan Sistem Informasi (SI). Hal ini disebabkan sistem informasi yang ada hanya dapat digunakan dalam pembayaran tagihan kepada bank pelaksana namun belum dapat digunakan dalam memverifikasi tagihan dan menilai ketepatan sasaran sehingga dibutuhkan pembuatan ataupun pengembangan sistem informasi.

3. Sub unsur pembinaan Sumber Daya Manusia (SDM) dalam unsur kegiatan pengendalian perlu dilakukan dengan adanya pendidikan dan pelatihan, karena dengan SDM yang handal dapat meningkatkan unsur kegiatan pengendalian yang mempunyai tujuan utama mengantisipasi agar risiko tidak sampai menjadi masalah.

\section{SIMPULAN}

Berdasarkan hasil analisis dan pembahasan, dapat disimpulkan hal-hal sebagai berikut:

1. Penerapan Sistem Pengendalian Intern belanja subsidi bunga kredit program dilakukan melalui unsur-unsur Sistem Pengendalian Intern. Konsep tiga lini pertahanan (Three Lines of Defense) telah diterapkan namun belum menjadi fokus dalam satu rangkaian yang utuh dari manajemen yang mengelola belanja subsidi bunga kredit program, Unit Kepatuhan Internal (UKI) di Ditjen Perbendaharaan dan Inspektorat Jenderal Kementerian Keuangan.

2. Evaluasi terhadap Sistem Pengendalian Intern (SPI) Belanja Subsidi Bunga Kredit Program melalui pengelola keuangan menunjukkan bahwa Unsur sistem pengendalian intern telah berjalan dengan baik. Nilai terendah terdapat pada unsur informasi dan komunikasi yang disebabkan karena sistem 34 informasi yang ada hanya terkait penyaluran dana dan tidak terkait ketepatan sasaran. Pada unsur kegiatan pengendalian terdapat indikator yang masih bernilai kurang terkait pembinaan SDM. Hal ini disebabkan karena tidak adanya pelatihan untuk pengelola keuangan belanja subsidi bunga kredit program.

\section{SARAN}

Berdasarkan hasil penelitian, beberapa hal yang perlu dipertimbangkan sebagai saran adalah sebagai berikut:

1. Memperluas objek penelitian yaitu seluruh kementerian yang terkait belanja subsidi bunga kredit program.

2. Memperluas cakupan responden penelitian dengan mengikutsertakan kementerian dan lembaga lain yang terkait dalam belanja subsidi bunga kredit program.

3. Penelitian selanjutnya diharapkan mengukur tingkat efektivitas sistem pengendalian intern dalam belanja subsidi bunga kredit program.

\section{DAFTAR PUSTAKA}

A. Faroby Falatehan. 2016. Analytical Hierarchy Process (AHP) Teknik Pengambilan Keputusan untuk Pembangunan Daerah. Indomedia Pustaka. Yogyakarta (ID).

Alek Murtin. 2015. Internal Control Peran dan Perkembangannya. Volume 1, No.1 tahun 2015, Hal 1-10. Jurnal Akuntansi dan Investasi UMY. (ID)

[BPK]. Badan Pemeriksa Keuangan Republik Indonesia. 2013. Laporan Hasil Pemeriksaan BPK RI atas Laporan Keuangan Pemerintah Pusat Tahun 2012. Laporan Hasil Pemeriksaan atas Sistem Pengendalian Intern. Jakarta.

[BPK]. Badan Pemeriksa Keuangan Republik Indonesia. 2014. Laporan Hasil Pemeriksaan BPK RI atas Laporan Keuangan Pemerintah Pusat Tahun 2013. Laporan Hasil 
Pemeriksaan atas Sistem Pengendalian Intern. Jakarta.

[BPK]. Badan Pemeriksa Keuangan Republik Indonesia. 2015. Laporan Hasil Pemeriksaan BPK RI atas Laporan Keuangan Pemerintah Pusat Tahun 2014. Laporan Hasil Pemeriksaan atas Sistem Pengendalian Intern. Jakarta.

[BPK]. Badan Pemeriksa Keuangan Republik Indonesia. 2016. Laporan Hasil Pemeriksaan BPK RI atas Laporan Keuangan Pemerintah Pusat Tahun 2015. Laporan Pemantauan Tindak Lanjut Hasil Pemeriksaan atas Laporan Keuangan Pemerintah Pusat Tahun 2007-2014. Jakarta.

Bambang Hartadi. 1999. Sistem Pengendalian Intern dalam Hubungannya dengan Manajemen dan Audit. BPFE-Yogyakarta. Yogyakarta. (ID)

Brejita Mamuaja. 2016. Analisis Efektivitas Penerapan Sistem Pengendalian Intern terhadap Kinerja Instansi Pemerintah di Dinas Pendapatan Kota Manado. Volume 4 No. 1 tahun 2016: 165-171. ISSN 23031174. Jurnal EMBA. (ID)

Dadang Suwanda dan Dailibas. 2016. Panduan Penerapan Sistem Pengendalian Intern Pemerintah. Penerbit PPM. Jakarta. (ID)

Dadang Suwanda dan Agus Purwoko. 2016. Menyusun Standard Operating Procedures Lembaga Pemerintah Berbasis Sistem Pengendalian Intern Pemerintah. Penerbit PPM. Jakarta. (ID)

Duwi Priyatno. 2012. Cara Kilat Belajar Analisis Data dengan Aplikasi SPSS 20. ANDI. Yogyakarta. (ID)

Direktorat Jenderal Perbendaharaan, Kementerian Keuangan RI. 2012. Laporan Keuangan Bagian Anggaran Bendahara Umum Negara Belanja Subsidi Bunga Kredit Program (999.07) Tahun 2011 audited. Jakarta.

Direktorat Jenderal Perbendaharaan, Kementerian Keuangan RI. 2013.
Laporan Keuangan Bagian Anggaran Bendahara Umum Negara Belanja Subsidi Bunga Kredit Program (999.07) Tahun 2012 audited. Jakarta.

Erniati. 2015. Pengaruh Kompetensi Sumber Daya Manusia (SDM), Sistem Pengendalian Internal (SPI), dan Kebijakan Akuntansi terhadap Kualitas Laporan Keuangan SKPD Kabupaten Bulukumba. Tesis Program Magister Akuntansi Fakultas Ekonomi dan Bisnis Universitas Hasanuddin Makassar (ID).

Feng, M., Li, Chan. dan McVay, Sarah. 2009. Internal Control and Management guidance. Volume 48 tahun 2009:190-209. Journal of Accounting and Economics.

M. Irsan Dalil 2013. Analisis Sistem Pengendalian Internal Pemerintah: Studi Kasus Pelaksanaan Pencairan Anggaran di Kantor Pelayanan Perbendaharaan Negara (KPPN) Jakarta I. Tesis Program Studi Magister Akuntansi Universitas Indonesia Jakarta (ID).

M. Djafar Saidi. 2011. Hukum Keuangan Negara. Rajawali Pers. Jakarta. (ID)

Nuning Hindriani, Iman Hanafi, Tjahjanudin Domai. 2012. Perencanaan dan Pelaksanaan Anggaran di Daerah (Studi pada Dinas Kesehatan Kabupaten Madiun). Volume 15 No.3 tahun 2012. ISSN:1411-99. E-ISSN:2338-1884. Wacana, jurnal sosial dan Humaniora. (ID)

Nurhasanah. 2016. Efektivitas Pengendalian Internal, Audit Internal, Karakteristik Instansi dan Kasus Korupsi (Studi Empiris di Kementerian/Lembaga). Volume 2 No.1 tahun 2016: 27-48. Jurnal Tata Kelola \& Akuntabilitas Keuangan Negara. (ID)

Pemerintah Republik Indonesia. 2008. Peraturan Pemerintah Nomor 60 Tahun 2008 tentang Sistem Pengendalian Intern Pemerintah. 
Jakarta. Sekretariat Negara RI. Jakarta. (ID)

Richard Anthony. 2016. Strategi Penguatan Sistem Pengendalian Intern Dalam Penatausahaan Barang Milik Daerah Pada Pemerintah Kabupaten Bogor. Tesis Sekolah Pascasarjana Institut Pertanian Bogor (ID).

Riduwan. 2010. Skala Pengukuran Variabel-Variabel Penelitian. Alfabeta. Bandung.

Soritaon Siregar. 2010. Kebijakan Subsidi di Tengah Ancaman Krisis Ekonomi. PT Adamantium Kreasi Cipta, Jakarta. (ID)
Sugiyono. 2014. Metode Penelitian Kuantitatif, Kualitatif dan $R \& D$. Alfabeta. Bandung. (ID)

Sugiyono. 2015. Statistika untuk Penelitian. Alfabeta. Bandung. (ID)

Sujianto, Agus Eko. 2007. Aplikasi Statistik dengan SPSS untuk Pemula. Prestasi Pustaka. Jakarta. (ID)

Susilawati dan Riana. 2014. Standar Akuntansi Pemerintah dan Sistem Pengendalian Intern sebagai Antesedan Kualitas Laporan Keuangan Pemerintah Daerah. Volume XI No.1 tahun 2014. ISSN: 1693-4482. STARStudy \& Accounting Research. (ID) 


\section{Lampiran 1. Skor persepsi responden terhadap unsur-unsur SPI belanja subsidi bunga kredit program}

1) Unsur Lingkungan Pengendalian

Rincian Skor Lingkungan Pengendalian

- Nilai maksimum berdasarkan skor tertinggi $=1,824$

- Nilai Minimum berdasarkan skor terendah $=456$

- Tingkat capaian responden

$$
=1,514
$$

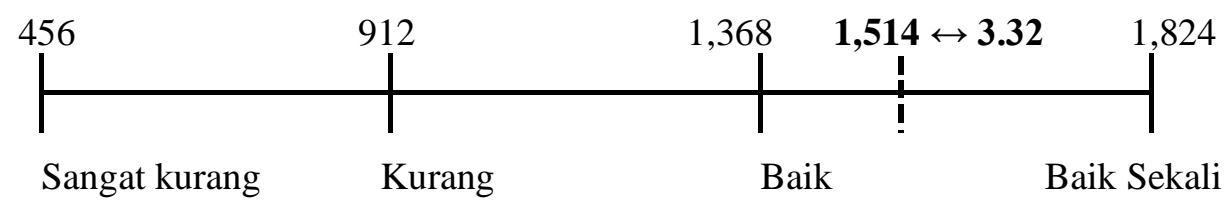

2) Unsur Penilaian Risiko

Rincian Skor Lingkungan Pengendalian

- Nilai maksimum berdasarkan skor tertinggi $=532$

- Nilai Minimum berdasarkan skor terendah $=133$

- Tingkat capaian responden

$$
=426
$$

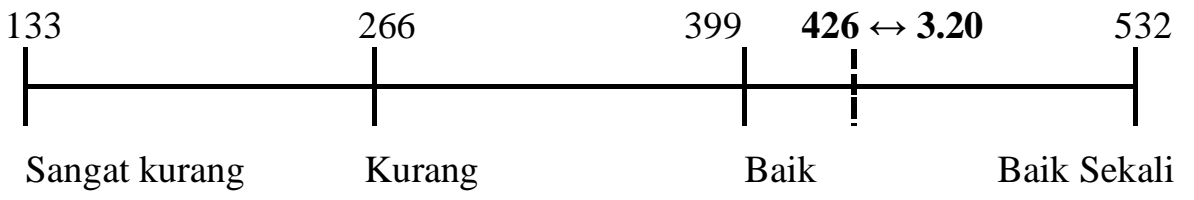

3) Unsur Kegiatan Pengendalian

Rincian Skor Lingkungan Pengendalian

- Nilai maksimum berdasarkan skor tertinggi $=1,672$

- Nilai Minimum berdasarkan skor terendah = 418

- Tingkat capaian responden $\quad=1,423$

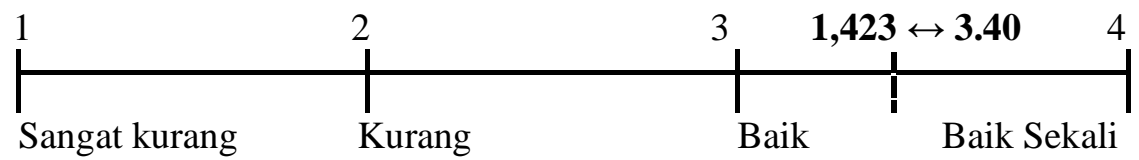

4) Unsur Informasi dan Komunikasi

Rincian Skor Lingkungan Pengendalian

- Nilai maksimum berdasarkan skor tertinggi $=380$

- Nilai Minimum berdasarkan skor terendah $\quad=95$

- Tingkat capaian responden $\quad=303$

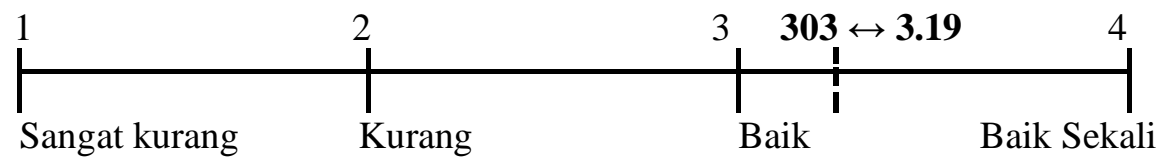

5) Unsur Pemantauan

Rincian Skor Lingkungan Pengendalian

- Nilai maksimum berdasarkan skor tertinggi $=456$

- Nilai Minimum berdasarkan skor terendah $\quad=114$

- Tingkat capaian responden $=377$

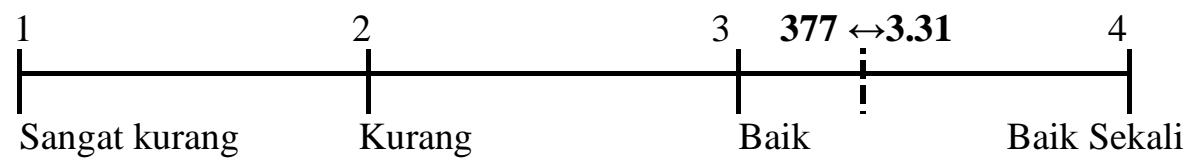




\section{Lampiran 2 Rencana Program dan Kegiatan}

\begin{tabular}{|c|c|c|c|c|c|}
\hline No & Strategi & Program & & Kegiatan & Lembaga \\
\hline $\bar{~} 1$ & $\begin{array}{l}\text { Pembuatan } \\
\text { Sistem } \\
\text { Informasi yang } \\
\text { terintegrasi } \\
\text { dalam } \\
\text { verifikasi dan } \\
\text { ketepatan } \\
\text { sasaran }\end{array}$ & $\begin{array}{l}\text { Program } \\
\text { Peningkatan } \\
\text { Efektivitas } \\
\text { Pengeluaran } \\
\text { Negara }\end{array}$ & 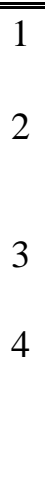 & $\begin{array}{l}\text { Pengkajian Sistem } \\
\text { Informasi } \\
\text { Pengembangan Sistem } \\
\text { Informasi } \\
\text { Implementasi Sistem } \\
\text { Informasi } \\
\text { Dukungan Manajemen } \\
\text { dan Dukungan Teknis } \\
\text { lainnya Ditjen } \\
\text { Perbendaharaan }\end{array}$ & $\begin{array}{l}\text { Direktorat SMI bekerja } \\
\text { sama dengan KPPN } \\
\text { Khusus Investasi, } \\
\text { Direktorat Sistem Informasi } \\
\text { dan Teknologi } \\
\text { Perbendaharaan, Itjen } \\
\text { Kementerian Keuangan, } \\
\text { Dit. Ang. Bidang } \\
\text { POLHUKAM dan BA } \\
\text { BUN, Pusintek Kemenkeu, } \\
\text { bank pelaksana. }\end{array}$ \\
\hline 2 & $\begin{array}{l}\text { Penyempurnaan } \\
\text { Peraturan dan } \\
\text { SOP }\end{array}$ & $\begin{array}{l}\text { Program } \\
\text { Pengelolaan } \\
\text { Perbendaharaan } \\
\text { Negara }\end{array}$ & 1 & $\begin{array}{l}\text { Pengkajian peraturan } \\
\text { Menteri Keuangan } \\
\text { Penyempurnaan } \\
\text { Peraturan Menteri } \\
\text { Keuangan } \\
\text { Penyusunan Peraturan } \\
\text { Menteri Keuangan } \\
\text { Penyusunan Peraturan } \\
\text { Dirjen Perbendaharaan } \\
\text { tentang SOP }\end{array}$ & $\begin{array}{l}\text { Dit SMI bekerjasama } \\
\text { dengan KPPN Khusus } \\
\text { Investasi, Itjen } \\
\text { Kementerian Keuangan, } \\
\text { Direktorat Sistem Informasi } \\
\text { \& Teknologi } \\
\text { Perbendaharaan, Bagian } \\
\text { OTL Setditjen } \\
\text { Perbendaharaan, Biro } \\
\text { Hukum Setjen Kemenkeu. }\end{array}$ \\
\hline 3 & $\begin{array}{l}\text { Pembentukan } \\
\text { Forum } \\
\text { Pengawasan } \\
\text { dan } \\
\text { Pengendalian }\end{array}$ & $\begin{array}{l}\text { Program } \\
\text { Monitoring dan } \\
\text { Evaluasi }\end{array}$ & 1 & $\begin{array}{l}\text { Koordinasi Pelaksanaan } \\
\text { Pengawasan \& } \\
\text { Pengendalian } \\
\text { Pelaksanaan Monitoring } \\
\text { \& Evaluasi } \\
\text { Pelaporan monitoring } \\
\text { dan evaluasi } \\
\text { Dukungan Manajemen } \\
\text { dan Dukungan Teknis } \\
\text { lainnya Ditjen } \\
\text { Perbendaharaan }\end{array}$ & $\begin{array}{l}\text { Dit SM bekerjasama } \\
\text { dengan KPPN Khusus } \\
\text { Investasi, Itjen Kemenkeu, } \\
\text { Direktorat Sistem } \\
\text { Perbendaharaan, Bagian } \\
\text { OTL Setditjen } \\
\text { Perbendaharaan, Biro } \\
\text { Hukum Setjen Kementerian } \\
\text { Keuangan, Kementerian } \\
\text { teknis terkait. }\end{array}$ \\
\hline 4 & $\begin{array}{l}\text { Pembinaan } \\
\text { SDM Pengelola } \\
\text { Subsidi Bunga }\end{array}$ & $\begin{array}{l}\text { Program } \\
\text { Peningkatan } \\
\text { Pengawasan } \\
\text { dan } \\
\text { Akuntabilitas } \\
\text { Aparatur } \\
\text { Negara }\end{array}$ & 1 & $\begin{array}{l}\text { Bimbingan Teknis SDM } \\
\text { pengelola subsidi bunga } \\
\text { kredit program } \\
\text { Diklat Teknis Substantif } \\
\text { pengelolaan subsidi } \\
\text { bunga kredit program } \\
\text { Pembinaan Pemantauan } \\
\text { dan Evaluasi }\end{array}$ & $\begin{array}{l}\text { Direktorat SMI bekerja } \\
\text { sama dengan KPPN } \\
\text { Khusus Investasi, Bagian } \\
\text { Sumber Daya Manusia } \\
\text { Setditjen Perbendaharaan, } \\
\text { BPPK, Pusdiklat Keuangan } \\
\text { Umum dan Kebendaharan } \\
\text { Negara. }\end{array}$ \\
\hline 5 & $\begin{array}{l}\text { Penilaian dan } \\
\text { Review } \\
\text { Pengendalian } \\
\text { Intern atas } \\
\text { Pelaporan } \\
\text { Keuangan }\end{array}$ & $\begin{array}{l}\text { Program } \\
\text { Pembinaan } \\
\text { akuntansi } \\
\text { Keuangan } \\
\text { Negara }\end{array}$ & 1 & $\begin{array}{l}\text { Pembinaan sistem dan } \\
\text { dukungan teknis } \\
\text { perbendaharaan } \\
\text { Pelaksanaan Monitoring, } \\
\text { Evaluasi \& Pelaporan }\end{array}$ & $\begin{array}{l}\text { Dit SMI bekerjasama } \\
\text { dengan KPPN Khusus } \\
\text { Investasi, Itjen } \\
\text { Kementerian Keuangan, } \\
\text { Direktorat Sistem } \\
\text { Perbendaharaan, UKI, Biro } \\
\text { Hukum Setjen Kementerian } \\
\text { Keuangan }\end{array}$ \\
\hline
\end{tabular}

